\title{
Gastric emptying of solids in man
}

\author{
S HOLT, ${ }^{*}$ J REID, T V TAYLOR, P TOTHILL, AND R C HEADING $\dagger$ \\ From the Departments of Therapeutics and Clinical Pharmacology, Clinical Surgery, and Medical Physics, \\ Royal Infirmary, Edinburgh, Scotland
}

SUMMARY The influence of the type and size of solid particles on their emptying from the stomach was studied using isotopically labelled chicken liver and inert particles in normal subjects and in patients who had undergone gastric surgery. In normal subjects, initial emptying of the liver was slower than that of inert particles both for large liver cubes $(1 \mathrm{~cm})$ and small cubes $(0 \cdot 3 \mathrm{~cm})$. Liver emptying subsequently accelerated to be faster than emptying of the inert particles. Overall emptying of the liver given as small cubes was faster than large cubes; $50 \%$ emptied in 50 minutes and 70 minutes respectively. In the postoperative subjects, emptying of the liver and of the inert particles was identical. The findings are consistent with the hypothesis that solid foods such as liver are ground down and 'liquefied' by the action of gastric peristalsis before being discharged to the duodenum. Ingested particle size appears to influence the rapidity of this process, which should be distinguished from the propulsive function of the stomach where small solid particles are concerned.

After the ingestion of a mixed liquid and solid meal, the liquid component empties from the stomach more rapidly than the solid. Although there is still debate about the relative importance of the proximal stomach $^{1}$ and of gastric peristalsis ${ }^{2}$ in controlling the emptying of liquids, it is generally agreed that the emptying of solids is controlled by the distal stomach, ${ }^{3}$ where peristaltic activity also serves to grind and mix the gastric contents before their delivery to the duodenum. Recent interest in the gastric emptying of solids has led to the development of several radioisotopically labelled solid foods suitable for study by scintigraphic methods. Liver labelled with technetium $99 \mathrm{~m}$ has been particularly favoured ${ }^{4-6}$ but emptying studies using bread ${ }^{7}$ and egg white, ${ }^{8}$ cellulose fibre, ${ }^{9}$ and bran ${ }^{10}$ have also been described.

We have previously reported studies of gastric emptying in man using small inert particles labelled with technetium $99 \mathrm{~m}$, which are added to a normal meal. ${ }^{11}$ These particles are emptied from the stomach in an approximately linear manner with time, corresponding to the pattern observed for solids which are normal dietary constituents. How-

\footnotetext{
* Present address: Dr S Holt, Department of Medicine, Division of Gastroenterology, 8-104A Clinical Sciences Building, University of Alberta, Edmonton, Alberta T6G 2G3, Canada.

$\dagger$ Address for correspondence: Dr R C Heading, Department of Therapeutics and Clinical Pharmacology, Royal Infirmary, Edinburgh, Scotland.

Received for publication 8 September 1981
}

ever, as the inert particles cannot be ground down within the stomach to produce the fine suspension of solid matter which normally enters the duodenum, their relevance to normal gastric function has been questioned. 512

One would expect that if the concept of grinding and 'liquefaction' of solid foods such as liver were correct, the pattern of gastric emptying of such food would differ from that of inert solid particles. A marked difference has been found in the dog, ${ }^{13}$ but, to our knowledge, Guller et al. ${ }^{14}$ have conducted the only published study in which emptying of the two types of solid has been directly compared in man and their results show linear emptying with time for both. The present investigation was therefore undertaken to repeat the comparison in man by performing simultaneous scintigraphic measurements of gastric emptying of chicken liver and inert particles which were both incorporated in a mixed solid-liquid meal.

\section{Methods}

Six normal male volunteers (aged 25-34 years) each underwent two studies of gastric emptying using a meal which consisted of isotopically labelled chicken liver (approximately $20 \mathrm{~g}$ ) and mashed potato (approximately $150 \mathrm{~g}$ ) to which ${ }^{99 \mathrm{~m}} \mathrm{Tc}$-labelled paper particles had been added. The particles consisted of 30 to 35 pieces of filter paper, each approximately $3 \mathrm{~mm}$ square which were impregnated with a total 
of $200 \mu \mathrm{Ci}{ }^{99 \mathrm{~m}} \mathrm{Tc}$ sulphur colloid. After drying, the paper was coated with Perspex. Experiments in vitro have shown that there is no significant elution of the isotope from these particles. ${ }^{11}$ The chicken liver was prepared as described by Meyer et al. ${ }^{4}$ except that $113 \mathrm{~m}$ In sulphur colloid was used in place of ${ }^{99 \mathrm{~m}} \mathrm{Tc}$ colloid. One hour after intravenous injection of the colloid $(3 \mathrm{mCi})$ the chicken was killed. The liver was then removed and cooked by boiling in water for five minutes. Checks on the water after cooking revealed no detectable elution of indium.

Approximately half the cooked chicken liver (containing 200-300 $\mu \mathrm{Ci}{ }^{113 \mathrm{~m}} \mathrm{In}$ ) was cut into cubes, either large $(1 \times 1 \times 1 \mathrm{~cm})$ or small $(0.3 \times 0.3 \times 0.3 \mathrm{~cm})$ and thoroughly mixed with the potato and the Tc-labelled particles. The subject was then given the meal together with a warm $\left(37^{\circ} \mathrm{C}\right)$ drink made up by dissolving three Oxo beef stock cubes in $400 \mathrm{ml}$ water. The subjects were asked to consume the drink evenly over the period during which they were eating the solid food, but otherwise no instructions were given concerning chewing or the speed of eating.

For one study, the subject ate the meal with the larger liver cubes and, in the other study, which was carried out on the following day, the subject was given a meal containing the liver cubes of small size. On each occasion gastric emptying of the two isotopes was measured using a rectilinear scanner set up for bilateral count detection. ${ }^{15}$ After correction of observed counts for physical decay of the radioisotopes, gastric emptying rates were calculated by linear regression of intragastric ${ }^{99 \mathrm{~m}} \mathrm{Tc}$ and $113 \mathrm{~m} \mathrm{In}$ against time. Comparisons of results were made using Student's $t$ test for pair differences.

After the investigation of normal subjects was completed, similar measurements were made on five patients with diarrhoea attributed to previous gastric surgery. The operations (four Polya gastrectomy, one vagotomy and pyloroplasty) had all been carried out because of peptic ulcer and had been performed one year or more previously; diarrhoea was defined as the production of fluid faeces with sufficient frequency that the patient was classified in Visick grade 3 or $4^{16}$ by an independent observer. After informed consent had been obtained, these patients were studied on one occasion only, using the large $(1 \mathrm{~cm})$ liver cubes and the Tc-labelled particles.

The simultaneous use of ${ }^{113 \mathrm{~m} I n}$ and ${ }^{99 \mathrm{~m}} \mathrm{Tc}$ in studies of gastric emptying was approved by the local Advisory Ethical Committee.

\section{Results}

Emptying patterns of the labelled liver and paper particles in the normal subjects are shown in Fig. 1. Ten minutes after ingestion of the meal, more of the particles than liver had been emptied from the stomach, irrespective of the size of liver cubes ingested (Fig. 1a and b). However, from 10 minutes onwards, emptying rates of the liver were faster than those of the particles (Table). Comparisons of the amounts of liver emptied at 120 minutes show that significantly more was emptied when it was given as small rather than large cubes (Fig. 2a). The two measurements made with paper particles give closely similar results (Fig. 2b).

In the post-gastric surgery patients, the liver and the paper particles emptied rapidly, $85 \%$ leaving the stomach in the first 10 minutes after ingestion of the meal (Fig. 3). Overall, there was no appreciable difference between the emptying of the two isotopes.

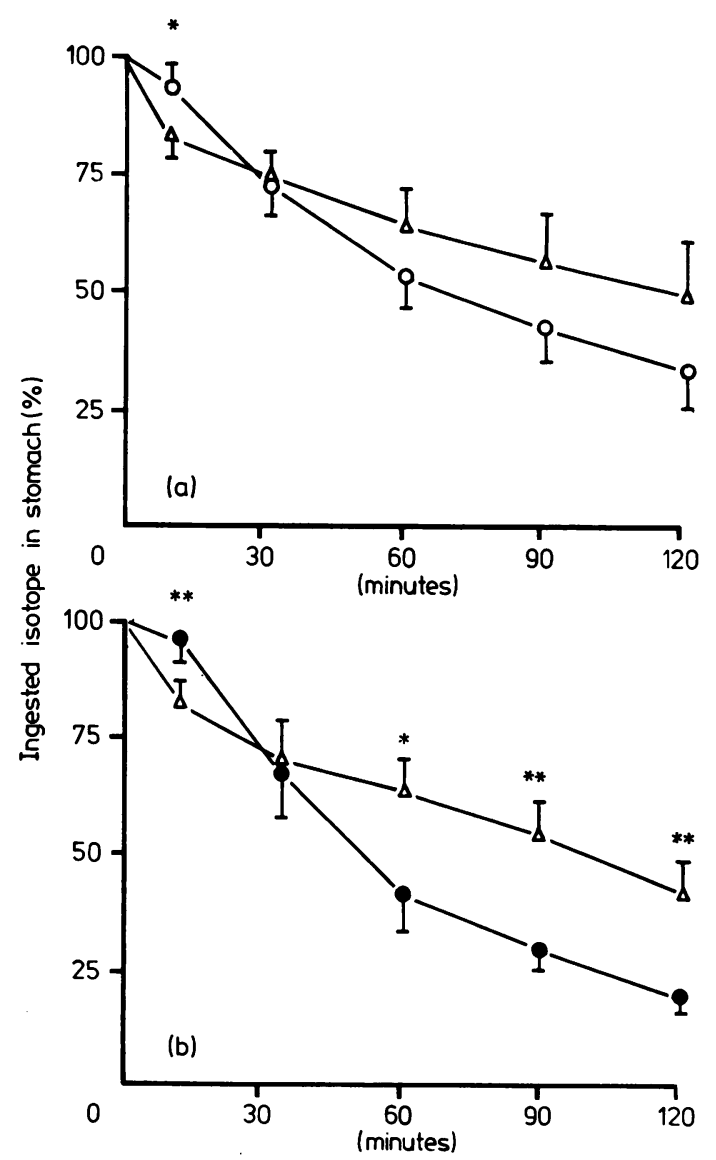

Fig. 1 Gastric emptying of ${ }^{113 m}$ In-labelled liver and $99 \mathrm{~m}$ Tc-labelled paper particles in six normal volunteers. (a) Simultaneous study of large liver cubes (O) and paper particles $(\triangle)$; (b) Simultaneous study of small liver cubes (O) and paper particles. Data are means $\pm S E M .{ }^{*} \mathrm{P}<0 \cdot 05$. ${ }^{* *} \mathrm{P}<0 \cdot 01$. 
Table Gastric emptying rates of $113 \mathrm{~m} / n$-labelled liver and 99m Tc-labelled paper particles during period 10-120 minutes after meal ingestion in six normal volunteers

\begin{tabular}{|c|c|c|}
\hline \multicolumn{2}{|c|}{$\begin{array}{l}\text { Emptying rates (\% ingested isotope } \\
\text { per min) of isotopically labelled } \\
\text { liver and paper particles }\end{array}$} & \multirow[b]{2}{*}{$\mathbf{P}$} \\
\hline Liver cubes & Paper particles & \\
\hline $\begin{array}{l}\text { Large } \\
0.58 \pm 0.07\end{array}$ & $0 \cdot 38 \pm 0 \cdot 11$ & $P<0.05$ \\
\hline $\begin{array}{l}\text { Small } \\
0.73 \pm 0.03 \\
P<0.05\end{array}$ & $\begin{array}{l}0.41 \pm 0.05 \\
\text { NS }\end{array}$ & $P<0.0025$ \\
\hline
\end{tabular}

Data are means \pm SEM. NS: not significant $=\mathrm{p}>0.05$ (one tail).

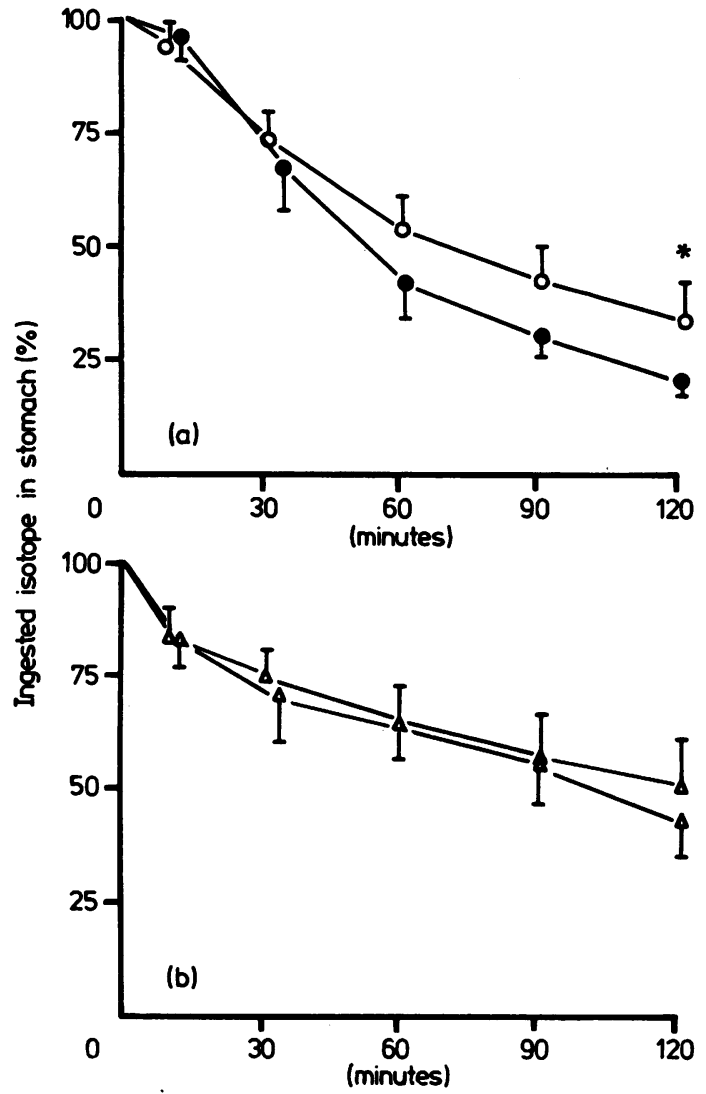

Fig. 2 Gastric emptying of $113 \mathrm{~m}$ In-labelled liver and $99 m$ Tc-labelled paper particles in six normal volunteers.

(a) Comparison of large $(O)$ and small (O) liver cubes.

(b)|Comparison of the two studies of paper particles $(\Delta)$.

Data $a_{i}$ means $\pm S E M .{ }^{*} \mathrm{P}<0.05$.

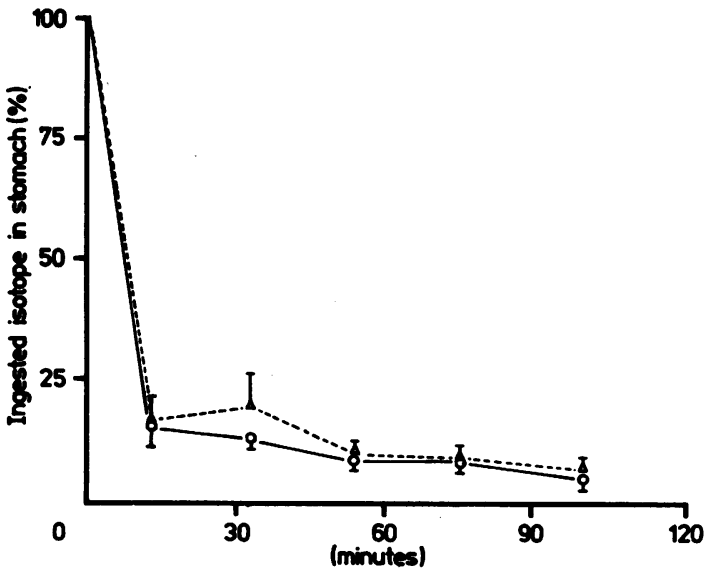

Fig. 3 Gastric emptying of $113 m$ In-labelled liver $(O)$ and $99 m \mathrm{Tc}$-labelled paper particles $(\Delta)$ in five patients who had undergone gastric surgery. Data are means $\pm S E M$.

\section{Discussion}

These results are consistent with evidence that ingested liver is 'liquefied' in the stomach before being passed through the pylorus. ${ }^{13} 1718$ Emptying of the liver in the normal subjects was initially slower and then faster than the inert particles, which might be expected if the liver is progressively transformed from a solid to a more rapidly emptied 'liquefied' form. The fact that the liver emptied a little more slowly than the paper particles during the first 10 minutes may perhaps be attributable to differences in shape of the two solids (liver cubes compared with paper squares) but this explanation remains unproven. However, the subsequent faster emptying of the liver when presented as small rather than large cubes implies that 'liquefaction' was more rapid with the smaller pieces of liver. In the dog, finely, ground or homogenised liver empties more rapidly than liver given as discrete cubes ${ }^{13}{ }^{17}$ and the same finding may reasonably be expected in man. ${ }^{19}$ The present results indicate that, in addition, the size of the liver cubes presented to the subject affects the rate at which the food is emptied from the stomach.

In the patients who had undergone gastric surgery, the liver and the inert particles emptied together. Rapid emptying took place during the first $\mathbf{1 0}$ minutes after meal ingestion, as observed in previous investigations. ${ }^{5811}$ This abnormality in patients who have undergone gastric surgery tends to be greater in those with postoperative diarrhoea than in those without symptoms 2021 and the selection of patients for the present study was intended to maximise the abnormality. The results show that, in such patients, gastric emptying of the two types of solid is indistinguishable. 
The present results differ from those of Guller et al. ${ }^{14}$ who found that in normal subjects ${ }^{198} \mathrm{Au}$-labelled liver emptied from the stomach more slowly than ${ }^{99 \mathrm{~m}} \mathrm{Tc}-$ labelled paper particles. However, in Guller's study, the half emptying time of the liver was almost four hours, whereas other investigators using labelled liver in comparable meals have recorded half emptying times between 75 and 110 minutes. ${ }^{56}$ The reasons for this difference are not clear. In the present study, which used a larger volume of fluid in the meal, half emptying times for the large and small liver cubes were approximately 70 minutes and 50 minutes respectively. It is, however, of considerable interest that, despite some differences in meal size and composition, and much slower emptying of the liver, the mean emptying rate of the inert particles recorded by Guller $(0.36 \%$ per minute) was very similar to the rates observed in the present study. This suggests that there are factors which influence the intragastric grinding of foods such as liver more profoundly than they influence the propulsive activity of the stomach for small solid particles. It would seem that these processes should be distinguished. Both these functions are usually attributed to gastric antral peristalsis, but more specific information about the mechanics of each is not available.

In normal subjects, the use of inert particles to study gastric emptying does not precisely represent the emptying of solid foods amenable to "liquefaction'. Nevertheless, under the conditions of the present study, the differences between the liver and inert particles were small, indicating that liquefaction is not an essential precondition of the gastric emptying of solids. The present findings are consistent with our previous suggestion ${ }^{11}$ that simultaneous use of inert particles and a liquid phase marker in a mixed solidliquid meal can provide physiologically relevant measurements which reflect aspects of the behaviour of liquids and solids in the stomach.

We are grateful to Dr J Wells, Poultry Research Institute, Edinburgh, for preparing the labelled chicken liver.

\section{References}

1 Wilbur BG, Kelly KA. Effect of proximal gastric, complete gastric and truncal vagotomy on canine gastric electrical activity, motility and emptying. Ann Surg 1973; 178:295-303.

2 Stemper TJ, Cooke AR. Gastric emptying and its relationship to antral contractile activity. Gastroenterology 1975; 69:649-53.

3 Dozois RR, Kelly KA, Code CF. Effect of distal antrectomy on gastric emptying of liquids and solids. Gastroenterology 1971; 61:675-81.
4 Meyer JH, MacGregor IL, Gueller R, Martin P, Cavalieri R. ${ }^{99 m} \mathrm{Tc}$ tagged chicken liver as a marker of solid food in the human stomach. Dig Dis Sci 1976; 21:296304.

5 MacGregor IL, Martin P, Meyer JH. Gastric emptying of solid food in normal man and after subtotal gastrectomy and truncal vagotomy with pyloroplasty. Gastroenterology 1977; 72:206-11.

6 Christian PE, Moore JG, Sorensen JA, Coleman RE, Welch DM. Effect of meal size and correction technique on gastric emptying time: studies with two tracers and opposed detectors. J Nucl Med 1980; 21:883-5.

7 Grimes DS, Goddard J. Gastric emptying of wholemeal and white bread. Gut 1977; 18:725-9.

8 Kroop HS, Long WB, Atavi A, Hansell JR. Effect of water and fat on gastric emptying of solid meals. Gastroenterology 1979; 77:997-1000.

9 Malagelada JR, Carter SE, Brown ML, Carlson GL. Radiolabelled fiber. A physiologic marker for gastric emptying and intestinal transit of solids. Dig Dis Sci $1980 ; 25: 81-7$

10 Sagar S, Little W, Pattens M, Grime S, Shields R. Technetium 99-labelled bran for measuring gastric emptying of solid food. Nucl Med Commun 1980; 1:169.

11 Heading RC, Tothill P, McLoughlin GP, Shearman DJC. Gastric emptying rate measurement in man. A double isotope scintiscanning technique for simultaneous study of liquid and solid components of a meal. Gastroenterology 1976; 71:45-50.

12 Malagelada JR. Quantification of gastric solid-liquid discrimination during digestion of ordinary meals. Gastroenterology 1977; 72:1264-7.

13 Hinder RA, Kelly KA. Canine gastric emptying of solids and liquids. Am J Physiol 1977; 233:E335-40.

14 Guller R, Nemec HW, Kyle L, Fridrich R. Zur messung der magenentleerung solider nahrung. Schweiz Med Wochenschr 1977; 107:442-6.

15 Tothill P, McLoughlin GP, Heading RC. Techniques and errors in scintigraphic measurements of gastric emptying. J Nucl Med 1978; 19:256-61.

16 Visick AH. A study of failures after gastrectomy. Ann Roy Coll Surg 1948; 3:266-84.

17 Meyer JH, Thomson JB, Cohen MB, Shadchehr A, Mandiola SA. Sieving of solid food by the canine stomach and sieving after gastric surgery. Gastroenterology 1979; 76:804-13.

18 Meyer JH, Ohashi H, Jehn D, Thomson JB. Size of liver particles emptied from the human stomach. Gastroenterology 1981; 80:1489-96.

19 Malagelada JR, Go VLW, Summerskill WHJ. Different gastric, pancreatic and biliary responses to solid-liquid or homogenized meals. Dig Dis Sci 1979; 24:101-10.

20 Colmer MR, Owen GM, Shields R. Pattern of gastric emptying after vagotomy and pyloroplasty. $\mathrm{Br}$ Med J $1973 ; 2: 448-50$

21 Millar JW, McLoughlin GP, Macleod IB, Heading RC The effect of vagotomy on gastric emptying of solid and liquid components of a meal. In: Duthie HL, ed. Gastrointestinal motility in health and disease. Lancaster: MTP Press, 1978:215-22. 
ADDENDUM

Since this paper was accepted for publication we have learned of the investigation by Bertrand et al. (Gastroenterologie Clinique et Biologique 1980; 4:770-6) in which gastric emptying of inert radio-opaque granules and isotopically labelled rabbit liver were compared and found to empty from the stomach at similar rates. 